\title{
Tobacco-attributable burden of cancer according to socioeconomic position in France
}

Gwenn Menvielle ${ }^{1}$, Ivana Kulhánová2 ${ }^{2}$ Joséphine Bryère ${ }^{3}$, Guy Launoy ${ }^{3,4,5}$, Daniel Eilstein ${ }^{6}$, Cyrille Delpierre ${ }^{7,8}$, Isabelle Soerjomataram ${ }^{2}$

${ }^{1}$ INSERM, Sorbonne Université, Institut Pierre Louis d'épidémiologie et de Santé Publique IPLESP, 75012 Paris, France

${ }^{2}$ Section of Cancer Surveillance, International Agency for Research on Cancer, Lyon, France

${ }^{3}$ Cancers and Preventions, U1086 INSERM-UCN, Centre François Baclesse, Caen, France.

${ }^{4}$ University Hospital Center (CHU) of Caen, Caen, France

${ }^{5}$ University of Caen Normandy, Caen, France

${ }^{6}$ Santé publique France, Saint-Maurice, France

${ }^{7}$ UMR 1027 INSERM, Faculty of medicine, Toulouse, France

${ }^{8}$ University of Toulouse III - Paul Sabatier, Toulouse, France

Corresponding author:

Gwenn Menvielle

Equipe de Recherche en Epidémiologie Sociale (ERES)

Institut Pierre Louis d'Epidémiologie et Santé Publique (IPLESP)

Inserm UMRS 1136 - Sorbonne Universités UPMC Faculté de médecine de Saint-Antoine

27 rue Chaligny 75012 Paris

France

Tel: +33 (0)1 86219206

Fax: +33 (0)1 44738462

Email: gwenn.menvielle@inserm.fr

Abstract (word count): 233

Manuscript (main text): 3566

Figures: 1

Tables: 3

References: 49

Article category: Cancer epidemiology

Abbreviations: PAF (population attributable fraction), SEP (socioeconomic position), EDI (European Deprivation Index), RR (relative risk), IR (incidence rate) 


\section{Novelty and impact}

In France, the population attributable fraction (PAF) to smoking for cancers linked to smoking increased from $56 \%$ among men with the highest socioeconomic position (SEP) to $70 \%$ among men with the lowest SEP and from $26 \%$ to $38 \%$ in women. In total, $27.5 \%$ of the excess cancer cases in the low-SEP groups in men and $43.4 \%$ in women could have been avoided if all SEP subgroups smoked as those with the highest SEP. This underlines the urgent need to apprehend the socioeconomic inequalities in cancer as a consequence of many interrelated determinants.

Key-words: Tobacco-related cancers, Incidence, Deprivation, PAF, France

Funding: This work was funded by the French National Cancer Institute (INCa, grant number 2015-002)

\section{Abstract}

Smoking is a major preventable cause of cancers and is increasingly concentrated among the most deprived individuals leading to increasing socioeconomic inequalities in the incidence of cancers linked to smoking. We aimed to estimate the tobacco-attributable cancer burden according to socioeconomic position in France. The analysis was restricted to cancer sites for which tobacco smoking was recognized as a risk factor. Cancer cases by sex, age group and European Deprivation Index (EDI) among people aged 30-74 between 2006 and 2009 were obtained from cancer registries covering approximately $20 \%$ of the French population. The tobacco-attributable burden of cancer according to EDI was estimated applying the population attributable fraction (PAF) computed with the Peto-Lopez method. The PAF increased from $56 \%$ in the least deprived EDI quintile to $70 \%$ in the most deprived EDI quintile among men and from $26 \%$ to $38 \%$ among women. In total, $28 \%$ of the excess cancer cases in the four most deprived EDI quintiles in men and $43 \%$ in women could be prevented if smoking in these 4 EDI quintiles was similar to that of the least deprived EDI quintile. A substantial smokingattributable burden of cancer by socioeconomic position was observed in France. The results highlight the need for policies reducing tobacco consumption. More comprehensive interventions integrating the various dimensions of health determinants and proportionate according to socioeconomic position may essentially contribute to the reduction of socioeconomic inequalities in cancer. 


\section{Introduction}

Smoking is a major preventable cause of morbidity and mortality from cardiovascular disease, chronic obstructive pulmonary disease, lung cancer as well as a range of other cancers, peptic ulcer and various other medical conditions. In 2010 in France it has been estimated that smoking was responsible for about 59,000 deaths in men and 19,000 deaths in women, accounting for $21 \%$ and $7 \%$ of all deaths respectively. A large part of these deaths are due to cancer: $66 \%$ in men and $42 \%$ in women. ${ }^{1}$

Smoking prevalence has remained stable between 2000 and 2016 in France, with 32\% of men and 26\% of women smoking in 2016. But this prevalence is socially distributed, with higher tobacco smoking among people from a lower socioeconomic group, and this social gradient in tobacco smoking is increasing. ${ }^{2-4}$

It has been shown that a higher level of tobacco smoking partly accounted for the higher incidence of lung cancer in low socioeconomic groups ${ }^{5-8}$ and that the contribution of smoking to relative inequalities in lung cancer incidence in France ranged from $22 \%$ for men with primary education to $31 \%$ for men with a high school degree when compared with men with a university degree. ${ }^{9}$ In addition to tobacco, other risk factors, such as behavioral, environmental, occupational or psychosocial conditions, are likely to contribute to the excess cancer risk in more deprived groups ${ }^{10}$. In particular, occupational exposures such as asbestos, silica, or formaldehyde, have been shown to explain a nonnegligible part of socioeconomic inequalities in lung ${ }^{11,12}$ and head and neck cancers ${ }^{13,14}$.

In addition to quantifying the relative contribution of risk factors to socioeconomic inequalities in cancer incidence, assessing the absolute number of cancer cases attributable to smoking by socioeconomic position (SEP) at a national level is important for policy makers to assess the population burden of smoking on social inequalities in cancer. However, such assessment based on national data is lacking.

The aim of this study is to estimate the tobacco-attributable cancer burden according to SEP in France by assessing the Population Attributable Fraction (PAF) and the number of cancer cases attributable to smoking by SEP at a national level.

\section{Methods}

\section{Data sources}

We used data from cancer registries (Calvados, Côte d'Or, Doubs, Finistère, Gironde, Haute-Vienne, Hérault, Isère, Loire-Atlantique, Manche, area of Lille, Bas-Rhin, Haut-Rhin, Saône-et-Loire, Somme, Tarn, and Vendée), which represent approximately $20 \%$ of the French population. Cancers diagnosed among people aged 30-74 between 2006 and 2009 were included. We studied the following cancers related to tobacco smoking according to IARC evaluations ${ }^{15}$ : lip and oral cavity (ICD-10: C00-C08), oropharynx (C09-C10, C12-C14), nasopharynx (C11), oesophagus (C15), stomach (C16), colon and rectum (C18-C20), liver (C22), pancreas (C25), larynx (C32), trachea, lung and bronchus (C33-C34), cervix uteri (C53), ovary (only mucinous cancer, C56), kidney and renal pelvis (C64-C65), urinary bladder (C67), acute myeloid leukaemia (C92.0). In the rest of the paper, we will refer to this group of cancers as cancers linked to smoking. 
As no individual socioeconomic characteristic is available in the French cancer registries, SEP was assessed using an ecological deprivation index which attributes the level of deprivation of his/her place of residence at diagnosis to each case recorded at the registry. We used the French version of the European Deprivation Index (EDI), calculated at the smallest geographical scale available (IRIS, about 2000 inhabitants). The methodology has been described elsewhere. ${ }^{16}$ Briefly, from the French part of the European Union Statistics on Income and Living Conditions (EU-SILC), an individual deprivation indicator is first developed from fundamental needs associated in the sample with objective and subjective poverty ${ }^{17}$, then ecological census variables that are the most closely related to the individual deprivation indicator are selected using logistic regressions. A categorical version of the EDI (quintiles calculated at the French level, each quintile includes $20 \%$ of the IRIS) was used.

The number of cancer cases was provided by age groups (30-59, 60-74), sex, cancer site and EDI quintile (see supplementary table 1 for the number of cancer cases observed over the 2006-2009 and the corresponding incidence rates). Due to the small number of cancer cases in some strata, we combined all four years 2006 to 2009. Population data by sex, age group and EDI quintile for the years 20062009 were obtained from the French national Statistics Institute.

\section{Calculation of the PAF}

Smoking status was not recorded at the cancer registries. Therefore we used an indirect method to assess the population attributable fraction (PAF) of the cancer burden attributable to smoking according to SEP. Although the PAF is a powerful and validated tool to assess the burden of smoking, this is a relatively parsimonious method. By sex, age group (30-59, 60-74) and EDI quintile, we computed the PAF to smoking for each cancer linked to smoking. The number of cancer cases attributable to smoking by EDI quintile was then obtained by multiplying the PAF by the number of cancer cases observed over the period 2006-2009. We then combined these figures to obtain the overall PAF for the age range $30-74$.

The PAF was computed using the indirect method proposed by Peto-Lopez, which has been specifically developed to assess the burden of tobacco smoking on cancer incidence. More information can be found elsewhere ${ }^{18,19}$. The indirect method assumes that the lung cancer rates in a specific population can be used to approximate the cumulative exposure of tobacco smoking in this population. The PAF and the number of cancer cases attributable to smoking are then computed separately for lung cancer and for the other cancer sites, using two different formulas.

The PAF to smoking for lung cancer incidence was calculated by the following formula:

$$
P A F_{\text {lung }}=\frac{N_{\text {lung }}^{\text {observed }}-A S R_{N S} * P}{N_{\text {lung }}^{\text {observed }}}
$$

$N_{\text {lung }}^{\text {observed }}$ is the number of observed lung cancer cases in France by sex, age group and EDI quintile. ASR $_{N S}$ is the lung cancer incidence rate among never-smokers. It was obtained from the EPIC study by sex and age group $(30-59,60-74)^{20}$. This information was not available by EDI quintile, so we used the same incidence rates among never smokers in all EDI quintiles. $\mathrm{P}$ is the observed population size in France by sex, age group and EDI quintile. 
For the other cancers linked to smoking, the traditional PAF formula from Levin was used, as incidence rates in never-smokers are not known and the associations with smoking are not as strong as that for lung cancer: ${ }^{21}$

$$
P A F=\frac{p_{s}(R R-1)}{1+p_{s}(R R-1)}
$$

$p_{s}$ is a proxy for smoking prevalence in the French population. This proxy reflects the average cumulative exposure to smoking in the population. Assuming the relative risks (RR) of the EPIC study ${ }^{22}$ apply to the French population, $p_{s}$ is the smoking prevalence that would have been necessary to produce the observed lung cancer incidence in France.

$p_{s}$ (by sex, age group and EDI quintile) can be expressed as

$p_{S}={\frac{P A F_{\text {lung }}}{\left(1-P A F_{\text {lung }}\right)\left(R_{\text {lung }}-1\right)}}^{18}$

The adjusted RRs quantified the association between current smoking and cancer incidence for specific cancer sites. The RRs differed by sex and cancer site, but they were the same for all age groups and EDI quintiles. They were obtained from the EPIC study and were adjusted for age, education, body mass index, physical activity, alcohol consumption, total energy intake and consumption of fruits and vegetables ${ }^{22}$.

The PAFs by cancer site, age group, sex and EDI quintile are presented in supplementary table 2 .

\section{Measure of inequalities in cancer incidence}

We quantified the contribution of smoking to socioeconomic inequalities in cancer incidence at the national level. All calculations were performed separately for men and women and by age group (30$59,60-74)$. We calculated the total number of cancers linked to smoking by EDI quintile by multiplying the observed incidence rates (IR) with the national population figures (average of the years 20062009). Using the PAF, we also computed the number of cancer cases attributable to smoking by EDI quintile.

We considered three hypothetical situations: i) no one ever smoked; ii) the four lower EDI quintiles smoked as the least deprived EDI quintile; iii) and the four lower EDI quintiles had the same IRs as the least deprived EDI quintile. The hypothetical situation i) provided an estimate of the maximal reduction in cancer IR that would be observed if smoking could be totally eliminated. To assess the quantitative burden of smoking on the observed socioeconomic inequalities in cancer incidence in France, we then computed the number of cancer cases that could be prevented in the hypothetical situations ii) and iii). The ratio between the cases prevented in these two hypothetical situations provides an estimate of the potential reduction in cancer burden if inequalities in smoking were to be eliminated. Details for the calculation are available in appendix.

\section{Results}

In France, the observed number of cancers linked to tobacco smoking increased with decreasing SEP and was especially high in the most deprived EDI quintile, as the result of both higher IR and larger 
population size (about $27 \%$ both in men and women) in this group (Table 1 ). The PAF to smoking increased with decreasing SEP from $56 \%$ in men living in the least deprived neighborhoods to $70 \%$ in men living in the most deprived neighborhoods and from $26 \%$ to $38 \%$ in women. The higher PAFs observed in men than in women mirror the higher burden of smoking in men. The PAFs differed by age group. Among men and women, the PAF was higher in the younger age groups i.e. 30-59 years. The age difference was pronounced in the more deprived EDI quintiles whereas the PAFs were almost identical in both age groups in the least deprived EDI quintile. The number of cancers attributable to smoking was substantially higher in men $(42,613)$ than in women $(9,376)$ and was highest in the age group 60-74 in men and in the age group 30-59 in women.

IRs by EDI quintile are presented in Figure 1. Both in men and women, IRs for cancers linked to tobacco smoking increased with decreasing SEP. If no one had ever smoked, the IRs would hardly differ by EDI quintile. However, IRs would be only slightly reduced if the four lower EDI quintiles smoked as the least deprived EDI quintile. The socioeconomic gradient would nevertheless still be observed.

Tables 2 and 3 assess the contribution of smoking to socioeconomic inequalities in cancer incidence at the national level. If the four lower EDI quintiles had the same IRs as the least deprived EDI quintile, 8,687 cancers cases in men and 2,737 in women could be prevented (Table 2). If the four lower EDI quintiles smoked as the least deprived EDI quintile, 2,388 cancer cases in men and 1,187 cancer cases in women could be prevented, most of them in the age group 30-59. Thus, if inequalities in smoking were eliminated, the excess cancer cases in the 4 most EDI quintiles would be reduced by $27.5 \%$ $(2,388 / 8,687)$ in men and $43.4 \%(1,187 / 2,737)$ in women. The proportions did not differ by sex in the age group 60-74 (around 30\%), but was much higher in women than in men in the age group 30-59 (48.1\% versus $26.3 \%)$.

The proportion of cancers linked to tobacco smoking that could be prevented if all the population smoked like the least deprived EDI quintile increased with decreasing EDI quintile, and was higher in the younger age group. If in the most deprived EDI quintile smoked like the least deprived EDI quintile, $10 \%$ of cancer cases in men and $13 \%$ in women could be prevented in the least deprived EDI quintile in the age group 30-59 compared to 5\% in men and women in the age group 60-74 (Table 3).

\section{Discussion}

\section{Summary of main findings}

We investigated the tobacco-attributable cancer burden according to SEP in France using the PAF methodology. This is a relatively crude method and the results should therefore not be interpreted as exact values but rather considered order of magnitude. Our results showed that if socioeconomic inequalities in smoking were removed, a significant part of the excess number of cancer cases in the 4 most deprived EDI quintiles both in men and women would be saved. Indeed, $27.5 \%$ of the excess cancers cases in the 4 most deprived EDI quintiles in men and $43.4 \%$ in women could be prevented if smoking in these $4 \mathrm{EDI}$ quintiles was similar to that of the least deprived EDI quintile. However, smoking only partly explained socioeconomic inequalities in the incidence of cancers linked to smoking, in particular in men. 


\section{Interpretation of the results}

The diffusion of smoking within the population follows a process that has been described as the smoking epidemic. ${ }^{23,} 24$ Over the whole process, smoking progressively becomes more concentrated among socially deprived groups and this tends to happen first in men and then in women. The contribution of smoking in socioeconomic inequalities in health increases as the smoking epidemic progresses into its final stage. Countries that are at an earlier stage of the smoking epidemic such as France, Italy or Spain will have a smaller contribution of smoking to socioeconomic inequalities than countries that are at the most advanced stage such as North America, Nordic European countries, the UK, and the Netherlands. ${ }^{4,}{ }^{25}$ Consistent with the evolution of the smoking epidemic, we observed an increase in PAF to smoking by decreasing SEP that was more pronounced in the younger age group (30-59), especially in women. Our results, in accordance with the literature, confirm that women in France have only recently reached the last stage of the smoking epidemic.

We estimated that if people in the most deprived EDI quintile had the same tobacco smoking prevalence as those in the least deprived EDI quintile, $10 \%$ of cancers linked to smoking in men and $13 \%$ in women in the younger age group could have been prevented. The respective figures for the older age group (60-74) were $5 \%$. In a previous paper on socioeconomic inequalities in smoking-related mortality during the 2000s, Kulik et al showed that if everybody smoked like tertiary educated, relative inequalities in lung cancer mortality would be reduced by $10 \%$ among French men and by $17 \%$ among French women for lung and laryngeal cancer. In total, $6 \%$ of lung and laryngeal cancer deaths among French men with up to lower secondary education and 2.5\% among French women with up to lower secondary education could be avoided. The percentage was much higher in the UK (30\% and $23 \%) .{ }^{25}$ Consistent with the literature ${ }^{5-8,12}$ smoking only partly explained socioeconomic inequalities in the incidence of cancers linked to tobacco smoking. Several hypotheses could explain these remaining inequalities. Occupational exposures to carcinogens have a high burden on lung, head and neck and bladder cancers especially in men. This is related in particular to higher exposure to asbestos, diesel engine exhaust and silica ${ }^{26}$. Studies have shown a substantial contribution of occupational exposures to socioeconomic differences in lung and head and neck cancer incidence. ${ }^{9,13,14,27}$ As these exposures are disproportionately concentrated in male occupations, this could partly account for the sex difference observed in our data. Other risk factors may also partly account for the higher incidence of cancers linked to tobacco smoking among the low socioeconomic groups because they are more prevalent in these groups (e.g. poor diet or physical inactivity) and/or because, the same level of exposure may be more harmful in these groups (e.g. air pollution). ${ }^{28-32}$ These risk factors may also interact, leading to a larger cancer risk in the low socioeconomic groups.

\section{Strengths and limitations}

Our estimates are based on population-based cancer registries data and therefore do not suffer from selection bias, known to be associated with people's SEP. We investigated incidence data over the period 2006-2009 because incidence data have not been geocoded for more recent years. The methodology used required lung cancer incidence rates among never smokers by age groups. As these 
rates were based on very small numbers in the age group $75+$ and consequently not reliable, the analyses were restricted to people aged below 75 .

In France, cancer registries do not record information on individual SEP. We therefore used an ecological deprivation index. Although this index was computed at the smallest geographical area available, our results may suffer from an ecological bias. ${ }^{33}$ The magnitude of the socioeconomic inequalities in health is smaller when SEP is measured with an ecological deprivation index rather than with an individual indicator. Sensitivity analyses using another deprivation index (FDep) ${ }^{34}$ yielded close results among men. Among women, the results differed in the oldest age group, with no association between PAF and SEP without any clear explanation for these discrepancies.

The RRs quantifying the relation between smoking and cancer incidence were obtained from the EPIC data, and we assumed that these applied to France. ${ }^{35}$ This assumption was necessary for practical reasons, as there are no high-quality literature reviews on the impact of smoking on cancer incidence for France. Nevertheless, there is an increasing body of evidence stating that, when the exposure is measured similarly, the RRs are similar across populations in different world regions. ${ }^{36}$ Additionally, the relative risks were assumed to be the same for all EDI quintiles. There is nevertheless an increasing body of literature suggesting that socioeconomic factors are biologically embodied and associated with different levels of epigenetic markers that in turn may be associated with a higher risk of diseases including cancer in the lower SEP. ${ }^{37,38}$ It is thus possible that the effect of the same level of tobacco smoking on cancer incidence may be higher in lower socioeconomic groups and that we slightly underestimated the number of cancer cases attributable to smoking in the more deprived EDI quintiles.

In our analyses, we used lung cancer IRs and RRs of cancer incidence associated with smoking from the European EPIC cohort because of the large differences in the smoking epidemic between the US and France. Sensitivity analyses using data from the CPS-II American survey as in the original publication presenting the Peto-Lopez method led to very similar conclusions.

The PAF calculations based on the indirect method do not require information on smoking in the population, but instead use the absolute lung cancer rates as a proxy of lifetime smoking in the population. Therefore, they do not suffer from reporting bias for tobacco smoking. However the lifetime smoking exposure in the population is derived from lung cancer incidence, and then applied to the other cancer sites, whereas this may not be the most relevant measure on tobacco smoking (and its pattern) for all cancer sites. In addition, this method assumes that lung cancer incidence among non-smokers is fairly small and roughly constant across populations; and hence the incidence (or mortality) rates of lung cancer in a specific population are largely determined by the cumulative exposure of this population to tobacco smoking. These assumptions generally hold in high income populations where lung cancer is rare among non-smokers even in polluted areas. Even radon and asbestos may cause only a small absolute risk among those who have never smoked. ${ }^{19}$ However, people with a low SEP are more likely to be exposed to other lung cancer carcinogens, namely occupational exposures that are concentrated in manual workers in particular for men, and we therefore cannot rule out that the use of the same lung cancer IR among never smokers for all EDI 
quintiles let to a slight overestimation of the role of smoking in socioeconomic inequalities in cancer incidence.

\section{Perspectives and conclusion}

We observed a substantial burden of smoking in socioeconomic inequalities in cancer incidence in France. Our results by age group, consistently with the available literature on socioeconomic differences in smoking by birth cohort, ${ }^{4}$ showed that this burden is going to dramatically increase in the most deprived groups in the coming years and even decades, especially among women. Our results thus highlight the need for policy efforts to reduce smoking in France in particular in the low socioeconomic groups. The time lag between smoking and cancer onset is of several decades for most cancers linked to tobacco smoking (lung, head and neck, pancreas, bladder, kidney) ${ }^{39}$. Therefore, any decrease in smoking would not affect cancer incidence before at least 20 years. However, other health outcomes such as cardiovascular and respiratory diseases would immediately benefit from a decrease in smoking.

Several tobacco control policies have been implemented in France during the last decade, in particular a gradual price increase since 2000, France now ranking as the European country with the third highest tobacco price (after UK and Ireland). Although the literature suggests that price increase is the most efficient tobacco control policy to decrease socioeconomic inequalities in smoking, ${ }^{40-42}$ this issue is still heavily discussed ${ }^{43-47}$ and the observed trends in smoking rates by SEP in France ${ }^{2,4}$ showed that such strategies largely failed to reduce both smoking rates and social inequalities in smoking. The tobacco control strategies implemented so far mostly focused on modifying individual behaviors. Policies, prevention campaigns and intervention ${ }^{48}$ should be implemented in a more comprehensive framework and address the social conditions and determinants where behaviors are rooted. ${ }^{49}$ Given the dramatic increase in educational differences in smoking in France among younger generations, such policies are urgently needed to limit the burden of smoking in socioeconomic inequalities in health in the future. In addition, our results show that smoking only partly explains socioeconomic inequalities in the incidence of cancer linked to tobacco smoking. This underlines the urgent need to apprehend the socioeconomic inequalities in cancer as the consequences of many interrelated determinants socially unequally distributed such as behavioral, occupational, environmental and housing exposures, to reduce social inequalities in cancer. 
1. Ribassin-Majed L and Hill C. Trends in tobacco-attributable mortality in France. Eur J Public Health 2015; 25: 824-8.

2. Pasquereau A, Gautier A, Andler R, Guignard R, Richard J, Nguyen-Thanh V, and le groupe Baromètre santé 2016. [Tabac et e-cigarette en France: niveaux d'usage d'après les premiers résultats du Baromètre Santé 2016] Tobacco and e-cigarette in France: levels of consumption according to the preliminary results from the 2016 Health Barometer. BEH 2017; 214.

3. Legleye $S$, Khlat M, Beck F, and Peretti-Watel P. Widening inequalities in smoking initiation and cessation patterns: a cohort and gender analysis in France. Drug Alcohol Depend 2011; 117: 233-41.

4. Bricard D, Jusot F, Beck F, Khlat M, and Legleye S. Educational inequalities in smoking over the life cycle: an analysis by cohort and gender. Int J Public Health 2016; 61: 101-9.

5. Menvielle $G$, Boshuizen $H$, Kunst AE, Dalton SO, Vineis $P$, Bergmann MM, Hermann S, Ferrari $P$, Raaschou-Nielsen O, Tjonneland A, Kaaks R, Linseisen J, Kosti M, Trichopoulou A, Dilis V, Palli D, Krogh V, Panico S, Tumino R, Buchner FL, van Gils CH, Peeters PH, Braaten T, Gram IT, Lund E, Rodriguez L, Agudo A, Sanchez MJ, Tormo MJ, Ardanaz E, Manjer J, Wirfalt E, Hallmans G, Rasmuson T, Bingham S, Khaw KT, Allen N, Key T, Boffetta P, Duell EJ, Slimani N, Gallo V, Riboli $\mathrm{E}$, and Bueno-de-Mesquita HB. The role of smoking and diet in explaining educational inequalities in lung cancer incidence. J Natl Cancer Inst 2009; 101: 321-30.

6. Nkosi TM, Parent ME, Siemiatycki J, and Rousseau MC. Socioeconomic position and lung cancer risk: how important is the modeling of smoking? Epidemiology 2012; 23: 377-85.

7. Mao Y, Hu J, Ugnat AM, Semenciw R, and Fincham S. Socioeconomic status and lung cancer risk in Canada. Int J Epidemiol 2001; 30: 809-17.

8. Hart CL, Hole DJ, Gillis CR, Smith GD, Watt GC, and Hawthorne VM. Social class differences in lung cancer mortality: risk factor explanations using two Scottish cohort studies. Int J Epidemiol 2001; 30: 268-74.

9. Menvielle G, Franck J, Radoi L, Sanchez M, Févotte J, Guizard AV, Stücker I, Luce D, and The ICARE study group. Quantifying the mediating effects of smoking and occupational exposures in the relation between education and lung cancer. Eur J Epidemiol 2016 epub.

10. McCartney G, Shipley M, Hart C, Davey-Smith G, Kivimaki M, Walsh D, Watt GC, and Batty GD. Why do males in Scotland die younger than those in England? Evidence from three prospective cohort studies. PLoS One 2012; 7: e38860.

11. Behrens T, Gross I, Siemiatycki J, Conway DI, Olsson A, Stucker I, Guida F, Jockel KH, Pohlabeln H, Ahrens W, Bruske I, Wichmann HE, Gustavsson P, Consonni D, Merletti F, Richiardi L, Simonato L, Fortes C, Parent ME, McLaughlin J, Demers P, Landi MT, Caporaso N, Zaridze D, Szeszenia-Dabrowska N, Rudnai P, Lissowska J, Fabianova E, Tardon A, Field JK, Dumitru RS, Bencko V, Foretova L, Janout V, Kromhout H, Vermeulen R, Boffetta P, Straif K, Schuz J, Hovanec J, Kendzia B, Pesch B, and Bruning T. Occupational prestige, social mobility and the association with lung cancer in men. BMC Cancer 2016; 16: 395.

12. Menvielle G, Franck J, Radoi L, Sanchez M, Févotte J, Guizard AV, Stücker I, Luce D, and The ICARE study group. Quantifying the mediating effects of smoking and occupational exposures in the relation between education and lung cancer. Eur J Epidemiol 2016; 31: 1213-1221.

13. Santi I, Kroll LE, Dietz A, Becher H, and Ramroth H. Occupation and educational inequalities in laryngeal cancer: the use of a job index. BMC Public Health 2013; 13: 1080.

14. Menvielle G, Luce D, Goldberg P, and Leclerc A. Smoking, alcohol drinking, occupational exposures and social inequalities in hypopharyngeal and laryngeal cancer. Int J Epidemiol 2004; 33: 799-806.

15. Humans IWGotEoCRt, personal habits and indoor combustions. IARC Monographs on the evaluation of carcinogenic risks to human. Vol. 100E. 2012, Lyon, France: International Agency for Research on Cancer. 
16. Pornet C, Delpierre C, Dejardin O, Grosclaude P, Launay L, Guittet L, Lang T, and Launoy G. Construction of an adaptable European transnational ecological deprivation index: the French version. J Epidemiol Community Health 2012; 66: 982-9.

17. Townsend $\mathrm{P}$, Phillimore $\mathrm{P}$, and Beattie $\mathrm{A}$, Health and Deprivation: Inequality and the North. 1988, London: Croom Helm.

18. Parkin DM. 2. Tobacco-attributable cancer burden in the UK in 2010. Br J Cancer 2011; 105 Suppl 2: S6-s13.

19. Peto R, Lopez AD, Boreham J, Thun M, and Heath C, Jr. Mortality from tobacco in developed countries: indirect estimation from national vital statistics. Lancet 1992; 339: 1268-78.

20. Thun M, Hannan L, Adams-Campbell L, Boffetta P, Buring J, Feskanich D, Flanders W, Jee S, Katanoda K, Kolonel L, Lee I, Marugame T, Palmer J, Riboli E, Sobue T, Avila-Tang E, Wilkens L, and Samet J. Lung cancer occurrence in never-smokers: an analysis of 13 cohorts and 22 cancer registry studies. PLoS Med 2008; 5: e185.

21. Levin ML. The occurrence of lung cancer in man. Acta Unio Int Contra Cancrum 1953; 9: 53141.

22. Agudo A, Bonet C, Travier N, Gonzalez CA, Vineis P, Bueno-de-Mesquita HB, Trichopoulos D, Boffetta P, Clavel-Chapelon F, Boutron-Ruault MC, Kaaks R, Lukanova A, Schutze M, Boeing H, Tjonneland A, Halkjaer J, Overvad K, Dahm CC, Quiros JR, Sanchez MJ, Larranaga N, Navarro C, Ardanaz E, Khaw KT, Wareham NJ, Key TJ, Allen NE, Trichopoulou A, Lagiou P, Palli D, Sieri S, Tumino R, Panico S, Boshuizen $\mathrm{H}$, Buchner FL, Peeters PH, Borgquist S, Almquist M, Hallmans G, Johansson I, Gram IT, Lund E, Weiderpass E, Romieu I, and Riboli E. Impact of cigarette smoking on cancer risk in the European prospective investigation into cancer and nutrition study. J Clin Oncol 2012; 30: 4550-7.

23. Lopez AD, NE C, and T P. A descriptive model of the cigarette epidemic in developed countries. Tob Control 1994; 3: 242-247.

24. Thun M, Peto R, Boreham J, and Lopez AD. Stages of the cigarette epidemic on entering its second century. Tob Control 2012; 21: 96-101.

25. Kulik MC, Hoffmann R, Judge K, Looman C, Menvielle G, Kulhanova I, Toch M, Ostergren O, Martikainen P, Borrell C, Rodriguez-Sanz M, Bopp M, Leinsalu M, Jasilionis D, Eikemo TA, and Mackenbach JP. Smoking and the potential for reduction of inequalities in mortality in Europe. Eur J Epidemiol 2013; 28: 959-71.

26. Brown T, Darnton A, Fortunato L, and Rushton L. Occupational cancer in Britain. Respiratory cancer sites: larynx, lung and mesothelioma. Br J Cancer 2012; 107 Suppl 1: S56-70.

27. Menvielle $G$, Boshuizen $H$, Kunst AE, Vineis $P$, Dalton SO, Bergmann MM, Hermann $S$, Veglia F, Ferrari P, Overvad K, Raaschou-Nielsen O, Tjonneland A, Kaaks R, Linseisen J, Palli D, Krogh V, Tumino R, Rodriguez L, Agudo A, Sanchez MJ, Arozena JM, Cirera L, Ardanaz E, Bingham S, Khaw KT, Boffetta P, Duell E, Slimani N, Gallo V, Riboli E, and Bueno-de-Mesquita HB. Occupational exposures contribute to educational inequalities in lung cancer incidence among men: Evidence from the EPIC prospective cohort study. Int J Cancer 2010; 126: 1928-35.

28. Malon A, Deschamps V, Salanave B, Vernay M, Szego E, Estaquio C, Kesse-Guyot E, Hercberg $\mathrm{S}$, and Castetbon K. Compliance with French nutrition and health program recommendations is strongly associated with socioeconomic characteristics in the general adult population. J Am Diet Assoc 2010; 110: 848-56.

29. Menai M, Charreire H, Feuillet T, Salze P, Weber C, Enaux C, Andreeva VA, Hercberg S, Nazare JA, Perchoux C, Simon C, and Oppert JM. Walking and cycling for commuting, leisure and errands: relations with individual characteristics and leisure-time physical activity in a crosssectional survey (the ACTI-Cites project). Int J Behav Nutr Phys Act 2015; 12: 150.

30. Raaschou-Nielsen O, Andersen ZJ, Beelen R, Samoli E, Stafoggia M, Weinmayr G, Hoffmann B, Fischer P, Nieuwenhuijsen MJ, Brunekreef B, Xun WW, Katsouyanni K, Dimakopoulou K, Sommar J, Forsberg B, Modig L, Oudin A, Oftedal B, Schwarze PE, Nafstad P, De Faire U, Pedersen NL, Ostenson CG, Fratiglioni L, Penell J, Korek M, Pershagen G, Eriksen KT, Sorensen M, Tjonneland A, Ellermann T, Eeftens M, Peeters PH, Meliefste K, Wang M, Bueno-de- 
Mesquita B, Key TJ, de Hoogh K, Concin H, Nagel G, Vilier A, Grioni S, Krogh V, Tsai MY, Ricceri F, Sacerdote C, Galassi C, Migliore E, Ranzi A, Cesaroni G, Badaloni C, Forastiere F, Tamayo I, Amiano $P$, Dorronsoro $M$, Trichopoulou A, Bamia C, Vineis $P$, and Hoek G. Air pollution and lung cancer incidence in 17 European cohorts: prospective analyses from the European Study of Cohorts for Air Pollution Effects (ESCAPE). Lancet Oncol 2013; 14: 813-22.

31. Padilla CM, Kihal-Talantikite W, Vieira VM, Rossello P, Le Nir G, Zmirou-Navier D, and Deguen S. Air quality and social deprivation in four French metropolitan areas--a localized spatiotemporal environmental inequality analysis. Environ Res 2014; 134: 315-24.

32. Deguen S, Petit C, Delbarre A, Kihal W, Padilla C, Benmarhnia T, Lapostolle A, Chauvin P, and Zmirou-Navier D. Neighbourhood Characteristics and Long-Term Air Pollution Levels Modify the Association between the Short-Term Nitrogen Dioxide Concentrations and All-Cause Mortality in Paris. PLoS One 2015; 10: e0131463.

33. Bryere J, Pornet C, Copin N, Launay L, Gusto G, Grosclaude P, Delpierre C, Lang T, Lantieri O, Dejardin $\mathrm{O}$, and Launoy $\mathrm{G}$. Assessment of the ecological bias of seven aggregate social deprivation indices. BMC Public Health 2017; 17: 86.

34. Rey G, Jougla E, Fouillet A, and Hemon D. Ecological association between a deprivation index and mortality in France over the period 1997 - 2001: variations with spatial scale, degree of urbanicity, age, gender and cause of death. BMC Public Health 2009; 9: 33.

35. Steenland $\mathrm{K}$ and Armstrong B. An overview of methods for calculating the burden of disease due to specific risk factors. Epidemiology 2006; 17: 512-9.

36. University $\mathrm{H}$, Washington Uo, University $\mathrm{JH}$, and Queensland Uo, GBD Study Operations Manual. 2009: World Health Organization.

37. Castagné R, Kelly-Irving M, Campanella G, Guida F, Krogh V, Palli D, Panico S, Sacerdote C, Tumino R, Kleinjans J, de Kok T, Kyrtopoulos $S$, Lang T, Stringhini $S$, Vermeulen R, Vineis $P$, Delpierre $\mathrm{C}$, and Chadeau-Hyam M, Biological marks of early-life socioeconomic experience is detected in the adult inflammatory transcriptome, in Sci Rep. 2016.

38. Kelly-Irving M, Mabile L, Grosclaude P, Lang T, and Delpierre C. The embodiment of adverse childhood experiences and cancer development: potential biological mechanisms and pathways across the life course. Int J Public Health 2013; 58: 3-11.

39. Sasco AJ, Secretan MB, and Straif K. Tobacco smoking and cancer: a brief review of recent epidemiological evidence. Lung Cancer 2004; 45 Suppl 2: S3-9.

40. DeCicca $P$ and McLeod L. Cigarette taxes and older adult smoking: evidence from recent large tax increases. J Health Econ 2008; 27: 918-29.

41. Thomas S, Fayter D, Misso K, Ogilvie D, Petticrew M, Sowden A, Whitehead M, and Worthy G. Population tobacco control interventions and their effects on social inequalities in smoking: systematic review. Tob Control 2008; 17: 230-7.

42. Siahpush M, Wakefield MA, Spittal MJ, Durkin SJ, and Scollo MM. Taxation reduces social disparities in adult smoking prevalence. Am J Prev Med 2009; 36: 285-91.

43. Franks $P$, Jerant AF, Leigh JP, Lee D, Chiem A, Lewis I, and Lee S. Cigarette prices, smoking, and the poor: implications of recent trends. Am J Public Health 2007; 97: 1873-7.

44. Peretti-Watel P, L'Haridon $O$, and Seror V. Responses to increasing cigarette prices in France: how did persistent smokers react? Health Policy 2012; 106: 169-76.

45. Peretti-Watel P, Constance J, Seror V, and Beck F. Cigarettes and social differentiation in France: is tobacco use increasingly concentrated among the poor? Addiction 2009; 104: 171828.

46. Regidor E, Pascual C, and Gutierrez-Fisac JL. Increasing the price of tobacco: economically regressive today and probably ineffective tomorrow. Eur J Cancer Prev 2007; 16: 380-4.

47. Breton $E$ and Sherlaw w. Examining tobacco control strategies and aims through a social justice lens: an application of Sen's capabilities approach. Public Health Ethics 2011; 4: 149-159.

48. Michie S, Brown J, Geraghty A, Miller S, Yardley L, Gardner B, Shahab L, McEwen A, Stapleton $\mathrm{J}$, and West R. Development of StopAdvisor: a theory-based interactive internet-based smoking cessation intervention. Transl Behav Med 2012; 2: 263-75. 
49. Commission on social determinants of health (CSDH), Closing the gap in a generation. Health equity through action on the social determinants of health. 2008, WHO: Geneva. 
Figure 1: Incidence rates (per 100,000 person-years) for cancers linked to tobacco smoking* by sex (A. men, B. women) and European Deprivation Index (EDI) quintile in different hypothetical situations regarding tobacco smoking (black: current situation, striped: no one has ever smoked, grey: the four lower EDI quintiles smoked as the least deprived EDI quintile) 2006-2009
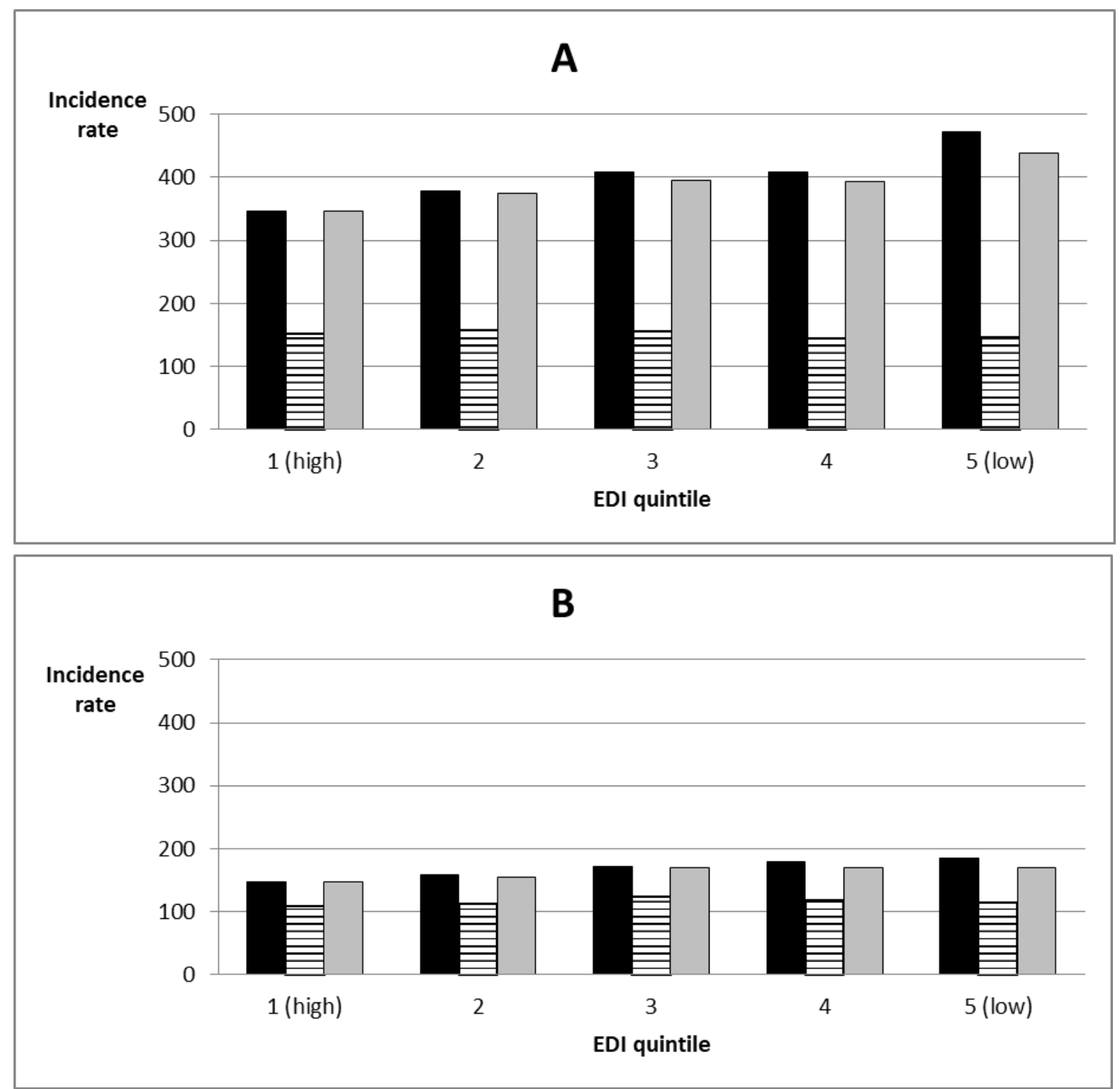

* cancers linked to tobacco smoking include the following cancer sites: lip and oral cavity (ICD-10: C00C08), oropharynx (C09-C10, C12-C14), nasopharynx (C11), oesophagus (C15), stomach (C16), colon and rectum (C18-C20), liver (C22), pancreas (C25), larynx (C32), trachea, lung and bronchus (C33-C34), cervix uteri (C53), ovary (only mucinous cancer, C56), kidney and renal pelvis (C64-C65), urinary bladder (C67), acute myeloid leukaemia (C92.0) 
Table 1: Number of cancers linked to tobacco smoking ( $\mathrm{N}_{\text {obs }}$ ), Population attributable fractions (PAF) to smoking and number of cancers attributable to smoking $\left(\mathrm{N}_{\text {att }}\right)$ by age group, sex and EDI quintile. France, average annual figures over the period 2006-2009

\begin{tabular}{|c|c|c|c|c|c|c|c|c|c|}
\hline \multirow[b]{2}{*}{ EDI quintile } & \multicolumn{2}{|c|}{$30-59$} & \multirow[b]{2}{*}{$\mathbf{N}_{\text {att }}$} & \multicolumn{2}{|c|}{$60-74$} & \multirow[b]{2}{*}{$\mathbf{N}_{\text {att }}$} & \multicolumn{2}{|c|}{$30-74$} & \multirow[b]{2}{*}{$\mathbf{N}_{\text {att }}$} \\
\hline & $N_{\text {obs }}$ & PAF & & $N_{\text {obs }}$ & PAF & & $N_{\text {obs }}$ & PAF & \\
\hline \multicolumn{10}{|l|}{ MEN } \\
\hline $\begin{array}{c}1 \text { (least } \\
\text { deprived) }\end{array}$ & 3827 & 56 & 2143 & 6252 & 57 & 3564 & 10079 & 56 & 5644 \\
\hline 2 & 4344 & 61 & 2650 & 6901 & 57 & 3934 & 11245 & 59 & 6635 \\
\hline 3 & 4690 & 64 & 3002 & 7403 & 61 & 4516 & 12093 & 62 & 7498 \\
\hline 4 & 5045 & 66 & 3330 & 8327 & 64 & 5329 & 13372 & 65 & 8692 \\
\hline $\begin{array}{c}5 \text { (most } \\
\text { deprived) }\end{array}$ & 8921 & 73 & 6512 & 11284 & 68 & 7673 & 20205 & 70 & 14144 \\
\hline Total & 26827 & & 17637 & 40167 & & 25016 & 66994 & & 42613 \\
\hline \multicolumn{10}{|l|}{ WOMEN } \\
\hline $\begin{array}{c}1 \text { (least } \\
\text { deprived) }\end{array}$ & 2047 & 26 & 532 & 2335 & 26 & 607 & 4382 & 26 & 1139 \\
\hline 2 & 2180 & 30 & 654 & 2630 & 28 & 736 & 4810 & 29 & 1395 \\
\hline 3 & 2450 & 33 & 809 & 2854 & 23 & 656 & 5304 & 28 & 1485 \\
\hline 4 & 2739 & 38 & 1041 & 3429 & 31 & 1063 & 6168 & 34 & 2097 \\
\hline $\begin{array}{c}5 \text { (most } \\
\text { deprived) }\end{array}$ & 4197 & 43 & 1805 & 4381 & 33 & 1446 & 8578 & 38 & 3260 \\
\hline Total & 13613 & & 4841 & 15629 & & 4508 & 29242 & & 9376 \\
\hline
\end{tabular}

EDI : European Deprivation Index, quintiles were computed among all French neighborhoods $\mathrm{N}_{\text {att }}=\mathrm{N}_{\mathrm{obs}} \times \mathrm{PAF} / 100$ 
Table 2: Number of cancers linked to tobacco smoking that could be prevented under different scenarios by age group and sex. Estimation at the French national level, annual average figures over the period 2006-2009

$\begin{array}{lll}30-59 & 60-74 & 30-74\end{array}$

\section{MEN}

Scenario 1: All the population had the same IR as the least deprived EDI quintile

$\begin{array}{lll}5131 & 3556 \quad 8687\end{array}$

Scenario 2: All the population smoked like the least

deprived EDI quintile

$1348 \quad 1040 \quad 2388$

Proportion of all cancers preventable under scenario $1^{*}$

$26.3 \%$ $29.3 \% \quad 27.5 \%$

\section{WOMEN}

Scenario 1: All the population had the same IR as the least deprived EDI quintile

Scenario 2: All the population smoked like the least deprived EDI quintile

Proportion of all cancers preventable under scenario $1^{*}$

$48.1 \% \quad 32.2 \% \quad 43.4 \%$

* Computed as follows: $26.3 \%$ = 1348 / 5131

Details for the calculations are available in the appendix 
Table 3: Proportion of cancers linked to tobacco smoking that could be prevented if all EDI quintiles smoked like the least deprived EDI quintile, by sex, age group and EDI quintile. Estimation at the French national level, annual average figures over the period 2006-2009

\begin{tabular}{lccc}
\hline EDI quintile & $30-59$ & $60-74$ & $30-74$ \\
\hline MEN & & & \\
1 (least deprived) & $0 \%$ & $0 \%$ & $0 \%$ \\
2 & $2.5 \%$ & $0.3 \%$ & $1.1 \%$ \\
3 & $4.4 \%$ & $2.1 \%$ & $3.0 \%$ \\
4 & $5.0 \%$ & $3.4 \%$ & $4.0 \%$ \\
5 (most deprived) & $9.9 \%$ & $5.5 \%$ & $7.4 \%$ \\
\hline WOMEN & & & \\
1 (least deprived) & $0 \%$ & $0 \%$ & $0 \%$ \\
2 & $3.0 \%$ & $1.1 \%$ & $1.9 \%$ \\
3 & $5.9 \%$ & $-2.3 \%$ & $1.3 \%$ \\
4 & $9.3 \%$ & $3.4 \%$ & $5.8 \%$ \\
5 (most deprived) & $13.3 \%$ & $4.8 \%$ & $8.7 \%$ \\
\hline
\end{tabular}

A negative percentage means that more cancers would be observed if all EDI quintiles smoked like the least deprived EDI quintile 


\section{Supplementary material: description of the calculations}

\section{Tobacco-attributable burden of cancer according to socioeconomic position in France}

Gwenn Menvielle, Ivana Kulhánová, Joséphine Bryère, Guy Launoy, Daniel Eilstein, Cyrille Delpierre, Isabelle Soerjomataram

\section{Computation of the incidence rates (IR)}

The incidence rates were computed by age group, sex and socioeconomic position (as measured with the European deprivation index (EDI) in quintiles). All incidence rates are computed by age group, sex and EDI quintile.

\subsection{Observed incidence rate}

For each EDI quintile $\mathrm{i}, \mathrm{IR}_{\mathrm{obs} \_ \text {EDI }=\mathrm{i}}=\mathrm{N}_{\mathrm{obs} \_ \text {EDIII }} / \mathrm{Popu}_{\mathrm{EDI}=\mathrm{i}}$

$\mathrm{N}_{\text {obs_EDl=i }}$ corresponds to the number of cancer cases observed over the period 2006-2009 in the area covered by a cancer registry. The figures are presented in Supplementary table 1.

$\mathrm{Popu}_{\mathrm{EDI}=\mathrm{i}}$ is the population living in the area covered by a cancer registry over the period 2006-2009.

\subsection{Incidence rate that would be observed if no one ever smoked}

For each EDI quintile $\mathrm{i}, \mathrm{IR}_{\text {no smoking_EDI=i }}=\mathrm{N}_{\text {no smoking_EDI=i }} / \mathrm{Popu}_{\mathrm{EDI}=\mathrm{i}}$

$\mathrm{N}_{\text {no smoking_EDI=i }}$ corresponds to the number of cancer cases that are not attributable to tobacco smoking and is computed as follows: $N_{\text {no smoking_EDl=i }}=N_{\text {obs_EDl=i }}-A_{E D I=i}$, with:

- $\mathrm{N}_{\text {obs_EDI=i }}=$ number of cancer cases observed over the period 2006-2009 in the area covered by a cancer registry

- $\quad \mathrm{A}_{\mathrm{ED}=\mathrm{i}}=$ number of cancer cases attributable to smoking over the period 2006-2009 in the area covered by a cancer registry

$A_{E D I=i}=N_{o b s} * P A F$

We use the age, sex and EDI quintile-specific PAF.

$\mathrm{Popu}_{\mathrm{EDI}=\mathrm{i}}$ is the population living in the area covered by a cancer registry over the period 2006-2009.

1.3. Incidence rate that would be observed if all EDI quintiles smoked like the least deprived EDI quintile

For each EDI quintile $\mathrm{i}, \mathrm{IR}$ excess smoking_EDI=i $=\mathrm{N}_{\text {excess smoking_EDI=i }} /$ Popu $_{\text {EDI=i }}$

$\mathrm{N}_{\text {excess smoking_EDI=i }}$ corresponds to the number of cancer cases that would be observed if all EDI quintiles smoked like the least deprived EDI quintile and is computed as follows: $\mathrm{N}_{\text {excess smoking_EDI=i }}=\mathrm{N}_{\text {obs_EDl=i }}$ $N_{\text {excessEDI=i, with: }}$ 
- $\quad \mathrm{N}_{\text {obs_EDI=i }}=$ number of cancer cases observed over the period 2006-2009 in the area covered by a cancer registry

- $\mathrm{N}_{\text {excess_EDI=i }}$ corresponds to the number of cancer cases due to higher smoking in each of the four lower EDI quintile when compared to the least deprived EDI quintile and is computed as follows: $N_{\text {excess_EDI=i }}=A_{E D I=i}-B_{E D I=i}$, with:

$0 \quad A_{E D I=i}=$ number of cancer cases attributable to smoking over the period 2006-2009 in the area covered by a cancer registry

$A_{E D I=i}=N_{\text {obs_EDl=i }} * P_{\text {A }}$ EDI=i

We use the age, sex and EDI quintile-specific PAF.

$0 \quad B_{E D I=i}=$ number of cancer cases attributable to smoking if all EDI quintiles smoked like the least deprived over the period 2006-2009 in the area covered by a cancer registry If all EDI quintiles smoked like the least deprived EDI quintile, then the PAF to smoking in all EDI quintiles would equal that observed in the least deprived EDI quintile.

$B_{E D l=i}=N_{\text {obs_EDl=i}} * P A F_{E D I=1}$

We use the age and sex-specific PAF of the least deprived EDI quintile $(E D I=1)$ for all EDI quintiles.

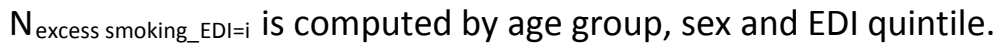

Popu $U_{E D I=i}$ is the population living in the area covered by a cancer registry over the period 2006-2009.

\section{Computation of the number of cancer cases at the national level}

The IR computed above are multiplied by the average yearly population living in France over the period 2006-2009 (Popu_France EDIII $_{\text {) }}$.

2.1. Number of cancer cases that could be prevented if the 4 most deprived EDI quintiles had the same incidence rates as the least deprived EDI quintile.

\begin{tabular}{|c|c|c|c|}
\hline $\begin{array}{c}\text { EDI } \\
\text { quintile }\end{array}$ & $\begin{array}{c}\text { Number of cancer cases } \\
\text { observed in France }\end{array}$ & $\begin{array}{l}\text { Number of cancer cases } \\
\text { that would be observed in } \\
\text { France if all EDI quintiles } \\
\text { had the same IR as the least } \\
\text { deprived EDI quintile } \\
\text { (2) }\end{array}$ & $\begin{array}{l}\text { Number of cancer cases } \\
\text { that could be } \\
\text { prevented if all EDI } \\
\text { quintiles had the same } \\
\text { IR as the least deprived } \\
\text { EDI quintile } \\
\text { (1) - (2) }\end{array}$ \\
\hline 1 & $\mathrm{IR}_{\text {obs_EDI }=1}$ * Popu_France EDI $=1_{1}$ & $\begin{array}{c}\text { IR } \text { obs_EDI=1 }^{*} \\
\text { Popu_France } \\
\text { EDI=1 }\end{array}$ & 0 \\
\hline 2 & $\mathrm{IR}_{\text {obs_EDI=2 }} *$ Popu_France EDI $=2$ & $\begin{array}{c}\text { IR }_{\text {obs_EDI }=1} * \\
\text { Popu_France } \\
\text { EDI=2 }\end{array}$ & $\mathrm{N}_{\text {prevented_EDI}=2}$ \\
\hline 3 & $\mathrm{IR}_{\text {obs_EDI=3 }} *$ Popu_France EDI $=3$ & $\begin{array}{c}R_{\text {obs_EDI }=1} * \\
\text { Popu_France EDI=3 }\end{array}$ & $\mathrm{N}_{\text {prevented_EDI=3 }}$ \\
\hline 4 & 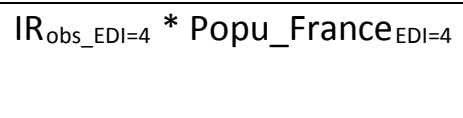 & $\begin{array}{c}R_{\text {obs_EDI }=1} * \\
\text { Popu_France } \\
\text { EDI=4 }\end{array}$ & $\mathrm{N}_{\text {prevented_EDI }=4}$ \\
\hline
\end{tabular}




\begin{tabular}{|c|c|c|c|}
\hline 5 & $\mathrm{IR}_{\text {obs_EDI }=5} *$ Popu_France $\mathrm{EDI}_{\mathbf{1}}$ & $\begin{array}{c}\mathrm{IR}_{\text {obs_EDI=1 }} * \\
\text { Popu_France } \\
\text { EDI=5 }\end{array}$ & $\mathrm{N}_{\text {prevented_EDI }=5}$ \\
\hline
\end{tabular}

$N_{\text {prevented }}=N_{\text {prevented_EDI }=2}+N_{\text {prevented_EDI }=3}+N_{\text {prevented_EDI }=4}+N_{\text {prevented_EDI }=5}$

2.2. Number of cancer cases that could be prevented if the 4 most deprived EDI quintiles smoked the least deprived EDI quintile.

\begin{tabular}{|c|c|c|c|}
\hline $\begin{array}{c}\text { EDI } \\
\text { quintile }\end{array}$ & $\begin{array}{c}\text { Number of cancer cases } \\
\text { observed in France }\end{array}$ & $\begin{array}{l}\text { Number of cancer cases that would } \\
\text { be observed in France if all EDI } \\
\text { quintiles smoked like the least } \\
\text { deprived EDI quintile }\end{array}$ & $\begin{array}{l}\text { Number of cancer } \\
\text { cases that could } \\
\text { be prevented if all } \\
\text { EDI quintiles } \\
\text { smoked like the } \\
\text { least deprived EDI } \\
\text { quintile } \\
\text { (1) - (2) }\end{array}$ \\
\hline 1 & $\mathrm{IR}_{\text {obs_EDI=1 }} *$ Popu_France EDI $=1_{1}$ & $\mid \mathrm{I}_{\text {excess smoking_EDI=1 }} *$ Popu_France ${ }_{\mathrm{EDI}=1}$ & 0 \\
\hline 2 & $\mathrm{IR}_{\text {obs_EDI }=2} *$ Popu_France ${ }_{E D I=2}$ & $\mathrm{IR}_{\text {excess smoking_EDI=2 }} *$ Popu_France EDI $=2$ & $\mathrm{~N}_{\text {prevented smoking_EDI }=2}$ \\
\hline 3 & $\mathrm{IR}_{\text {obs_EDI=3 }} *$ Popu_France EDI=3 & $\mid \mathrm{IR}_{\text {excess smoking_EDI }=3} *$ Popu_France EDI $=3$ & $\mathrm{~N}_{\text {prevented smoking_EDI }=3}$ \\
\hline 4 & $\mathrm{IR}_{\text {obs_EDI=4 }} *$ Popu_France EDI $=4$ & IR excess smoking_EDI=4 $^{*}$ Popu_France EDI $=4_{4}$ & $\mathrm{~N}_{\text {prevented smoking_EDI }=4}$ \\
\hline 5 & $\mid R_{\text {obs_EDI }=5} *$ Popu_France ${ }_{E D \mid=5}$ & IR excess smoking_EDI=5 $^{*}$ Popu_France ${ }_{\text {EDI }=5}$ & $\mathrm{~N}_{\text {prevented smoking_EDI }=5}$ \\
\hline
\end{tabular}

$\mathrm{N}_{\text {prevented smoking }}=\mathrm{N}_{\text {prevented smoking_EDI }=2}+\mathrm{N}_{\text {prevented smoking_EDI=3 }}+\mathrm{N}_{\text {prevented smoking_EDI }=4}+\mathrm{N}_{\text {prevented smoking_EDI=5 }}$

\section{Assumptions taken and potential impact on the results}

\section{Computation of the PAF for lung cancer}

Assumption: The same lung cancer incidence among non-smokers is observed in all EDI quintiles, hence incidence rates of lung cancer in a specific population are largely determined by the cumulative exposure of this population to tobacco smoking.

Potential impact on the results: Incidence rates among never smokers may be higher among people with a low SEP, because they are more likely to be exposed to other lung cancer carcinogens, namely occupational exposures that are concentrated in manual workers in particular for men.

Therefore, we may have slightly overestimated the PAF for lung cancer in the lower EDI quintiles.

\section{Computation of the PAF for the other cancers linked to smoking}

Assumption: The RRs quantifying the relation between smoking and cancer incidence were assumed to be the same for all EDI quintiles. There is nevertheless an increasing body of literature suggesting that socioeconomic factors are biologically embodied and associated with different levels of epigenetic markers that in turn may be associated with a higher risk of diseases including cancer in the lower SEP. 
Potential impact on the results: It is thus possible that the effect of the same level of tobacco smoking on cancer incidence may be higher in lower socioeconomic groups and the RR may be higher in the lower EDI quintiles.

Therefore, we may have underestimated the PAF in the lower EDI quintiles.

\section{Computation of the final combined PAF for all cancers linked to smoking}

There is both an overestimation of the PAF for lung cancer and an underestimation of the PAF for the other cancers linked to smoking. It is therefore impossible to say if the final combined PAF for all cancers linked to smoking was overestimated or underestimated in the lower EDI quintiles.

In any case, the least biased PAF will be that computed in the least deprived EDI quintile. 